\title{
No controverso desafio da educação inclusiva: Um convite para pensar a complexidade humana ${ }^{1}$
}

\author{
Roque Strieder ${ }^{\mathrm{i}}$
}

Universidade do Oeste de Santa Catarina, Brasil

Arnaldo Nogaroii

Universidade Regional Integrada do Alto Uruguai e das Missões, Brasil

Resumo

Neste texto reconhece-se que fazer educação inclusiva exige olhar o ser humano de modo singular em contextos multidimensionais. Nessa perspectiva, chama para a discussão a fragilidade do reconhecimento das diferenças e a importância da participação da filosofia da educação como catalizadora dos debates sobre a educação inclusiva. O objetivo é investigar possíveis contribuições da filosofia da educação como desafio para uma melhor compreensão de como ações inclusivas podem ser potencializadas no universo da complexidade e das atitudes transdisciplinares. O texto traz suportes teóricos sobre a atitude transdisciplinar e as possibilidades, no universo dessas atitudes, de uma contribuição para qualificar reflexões e ações inclusivas. Reconhece que a educação inclusiva existe em potencial e Ihe falta atualização. Destaca que a transdisciplinaridade e a filosofia da educação podem conduzir as reflexões para reconhecer a complexidade da condição humana para depois olhar para o interior de si buscando compreender-se a partir do outro.

Palavras-chave

Educação inclusiva; Filosofia da educação; Transdisciplinaridade 
De nada adianta desarmar todos os homens. Eles continuarão a se matar aos socos, se os espíritos não forem pacificados. E, na primeira oportunidade, produzirão máquinas ainda mais mortíferas para se destruir mutuamente.

(Weill, 1993, p. 30)

\section{Considerações iniciais}

No seio dos debates da filosofia da educação já não pode ficar ausente a temática da educação inclusiva, pois diante da complexidade e das inúmeras variáveis envolvidas na temática poucos são os consensos. É salutar verificar que as chances da educação inclusiva aumentam se reconhecermos a importância de conceber o ser humano como complexo e envolto em dimensões biológicas, históricas, psíquicas, mentais, sociais, culturais e ecológicas. Nessa visão multidimensional, a filosofia da educação pode contribuir para ampliar a compreensão e propor a conjugação de diferentes concepções e opções, aparentemente excludentes, opostas e contrárias, porque cria-se uma predisposição para aceitar o que acontece em outros níveis de realidade. A proximidade para com a filosofia da educação, necessária e fundamental, propõe o afastamento de verdades únicas e absolutas e reconhece que toda e qualquer posição intransigente e prepotente nega a interdependência de fenômenos e processos, bem como a complexidade das realidades mutantes e plurais.

Está no cerne da filosofia da educação que os fenômenos educacionais, tal como os seres humanos, só podem ser compreendidos em contextos multirreferenciais de conexões e vínculos, formando uma trama rizomática (Deleuze \& Guattari, 1995). Nessa trama, a educação inclusiva é expressão de vida, expressão do encontro de processos vitais e cognitivos (Assmann, 2005), uma vez que vida e aprendizagem não se separam. E, se a vida é produzida a partir de uma organização autopoiética (Maturana \& Varela, 1995), as relações e interações que se auto-eco-organizam garantem a dinâmica da vida. Então, faz sentido a afirmação de Maturana (2000): "Se não vemos o outro como um outro legítimo, não nos importamos, esse é o nosso problema. Não vemos, não expandimos nossa visão, agimos colocando fronteiras" (p. 99).

Particularmente aqui, sem menosprezar ou desconsiderar as inúmeras outras entradas e variáveis, necessárias nas reflexões e ações inclusivas, 
deseja-se destacar a importância da filosofia da educação no desafio de uma melhor compreensão de como ações inclusivas podem ser potencializadas no universo da complexidade e das atitudes transdisciplinares. A pretensão é estender nossa compreensão, em forma de convite, para a importância dos debates da filosofia da educação em relação a contribuições da complexidade e da atitude transdisciplinar.

A transdisciplinaridade é mais uma das vozes que, nutrida na complexidade, convida educadores e educandos a criarem ambientes e contextos formativos mais dinâmicos e flexíveis. A transdisciplinaridade, pautada no princípio da cooperação e da solidariedade, realiza cenários de respeito às diferenças e reconhece a diversidade cultural como forma de enriquecer experiências individuais e coletivas.

Ao reconhecer-se a transdisciplinaridade como um indicativo, reflexivo e filosófico, favorável à educação inclusiva, fica reforçado que um dos grandes fatores de inclusão, não redutível às propriedades dos diferentes indivíduos, está presente no seio das coletividades humanas, como proposto na lógica do Terceiro Incluído - uma lógica que encontrou seu berço na física quântica e desde então tem gerado um modelo emergente de conhecimento, mostrando a "coexistência entre pares de contraditórios mutuamente exclusivos" (Nicolescu, 1999, p. 29). A reflexão filosófica a partir do Terceiro Incluído pode ser uma contribuição efetiva para transformar nossa mentalidade, seja em relação a concepções de ser humano como em relação a significados das experiências educativas. Se reconhecermos as insuficiências, as fragilidades e a existência de arbitrariedades nas lógicas que sustentam ordenamentos sociais e culturais, pode-se contribuir para transformar mentalidades pedagógicas e educativas no que se refere a valores e atitudes, a visões e modos de vida.

Nem no contexto da filosofia da educação nem nos contextos das experiências educativas as mudanças de mentalidade se fazem pela via da simplificação, ou por meio de vertentes da lógica instrumental. São mudanças que envolvem reflexões exigentes e abertas sobre educação, sobre ser humano, sobre o modo de fazer sociedade, numa contemporaneidade que se constitui ao ser realizada em contextos complexos e mutáveis. Trata-se de uma busca em referenciais teóricos que, segundo Marconi e Lakatos (2008), não são uma mera repetição do que já foi escrito sobre um determinado 
assunto, mas uma investigação de um tema sob enfoques diferentes para chegar a conclusões inovadoras. E, como toda a atividade de pesquisa é colaborativa, estávamos no encalço de passos seguidos por outros pensadores, nos beneficiamos de seus trabalhos e princípios e - porque não dizer? - de suas práticas.

Entendemos que o olhar da filosofia da educação para os suportes teóricos da atitude transdisciplinar referenciam possibilidades de enriquecimento dos debates sobre educação inclusiva, ampliando as discussões e compreendendo que também existem interesses ideológicos como o de ser mais um mecanismo de exclusão ou dispositivo para governar populações (Foucault, 1999). A contribuição das reflexões da filosofia da educação permite renovar a esperança de acolhida ao outro, pois a acolhida ao outro potencializa a educação inclusiva.

\section{Trajetória educativa e a mutabilidade dos cenários}

Há um bom e significativo espaço temporal, a filosofia da educação alerta sermos frutos de uma ciência, de uma sociedade e de uma estrutura de concepções, plantadas em nossas mentalidades, que, historicamente, foram exigindo e estabelecendo regras de pertencimento. $\mathrm{Na}$ atualidade, o ideal de ser humano atrai-nos ainda, preferencialmente, para a lógica da homogeneidade.

Nem todos os modos de pensar do Renascimento, do lluminismo e mesmo da Modernidade como um todo, como também da chamada Pósmodernidade, caminham numa direção humanizadora. O cenário dos primórdios da Modernidade também concebeu a visão cartesiana e estática de mundo, como entidade ordenada e homogênea. Essa visão, transformada em paradigma, tem em Descartes, século XVII, seu fundador. Com uma visão fechada e ternária de ser humano - corpo, mente e espírito -, o cartesianismo firma a concepção mecanicista, como escreve Filho (2007): um "desabrochar da visão mecanicista, separativista e cientificista"; e, com "o separativismo mecanicista, a existência é reduzida à dimensão física" (p. 3). O paradigma cartesiano e mecanicista influenciou fortemente o modo de ser, o modo de vida e o modo de fazer ciência ao longo da Modernidade. 
Segundo Morin e Le Moigne (2000), em múltiplos domínios, portanto, a inteligência parcelada, compartimentada, mecânica, disjuntiva, reducionista, destrói o complexo do mundo em fragmentos disjuntos, fraciona os problemas, separa aquilo que está junto, unidimensionaliza o multidimensional:

É uma inteligência ao mesmo tempo míope, daltônica, zarolha; ela acaba frequentemente por tornar-se cega. Ela destrói na origem as possibilidades de compreensão e de reflexão, eliminando também as chances de julgamento correto ou de uma visão a longo prazo. (p. 94)

O dualismo cartesiano que fragmenta o ser humano - res cogitans e res extensa - tornou-se base para conhecer os fenômenos e as "coisas" naturais. Também serviu de referência para organizar e lidar com a população ${ }^{2}$, lidar com os processos educacionais e os processos de ensino e aprendizagem nas escolas. A sociedade atual configura-se ainda com base no ideal cartesiano, como escreve Santos (2005):

As estruturas e normas universitárias por longos anos têm se apoiado nos princípios cartesianos (fragmentação, descontextualização, simplificação, redução, objetivismo e dualismo). Esse modo cartesiano de ser direciona o olhar das pessoas exclusivamente para o que é objetivo e racional, desconsiderando a dimensão da vida e da cotidianeidade: a emoção, o sentimento, a intuição, a sensibilidade e a corporeidade. (p. 2)

Apesar de a ciência contemporânea mostrar que a concepção mecanicista do universo, de sociedade e de ser humano deixou de ser defensável, sob o ponto de vista estritamente científico, a educação contemporânea ainda privilegia concepções baseadas nessa visão. As consequências sociais desses equívocos educacionais são fortes e contribuem para a consolidação de um modo de vida marcado por relações de desencontros, seja em âmbito familiar, escolar, social ou profissional.

Bem sabemos, como muitas reflexões em filosofia da educação sustentam, que uma base familiar fragilizada fortalece a tendência para a libertação de obrigações éticas e de corresponsabilidade. Significa, por outro lado, predisposições para a vivência das exigências aceleradas, em que muitos laços humanos ficam desestruturados, sobrando mais dor e sofrimento do que podemos suportar (Maturana \& Yáñez, 2009). Para Bauman (2001), as consequências dessas transformações humanas e sociais aceleradas se concentram na dissolução dos laços afetivos e sociais. 
No universo da filosofia da educação também estão presentes reflexões questionadoras sobre a dimensão da lógica capitalista e tecnocientífica. Diante da supremacia da mesma, assistimos passivos à proliferação de políticas econômicas que negam aos mais pobres um lugar e uma parte dos recursos naturais. Sustenta-se essa miséria mesmo sabendo que a paz mundial e relacional está intrinsecamente vinculada à erradicação da pobreza (Ricoeur, 2006). Persiste, assim, como ilusória toda e qualquer tentativa de lidar com o problema da pobreza no âmbito da ortodoxia do capitalismo pregado e praticado, atualmente.

Os desafios da educação inclusiva encontram-se profundamente atrelados à dinâmica das reflexões filosóficas e pedagógicas, propondo erradicar a pobreza, o analfabetismo e a proibição da livre manifestação. É nesse sentido que Martha Nussbaum (2003, cit. em Hermann, 2010) considera que quem

se dedica a escrever ou ensinar filosofia é uma pessoa afortunada como poucos seres humanos o são, ao poder dedicar sua vida à formulação dos pensamentos e sentimentos mais profundos acerca dos problemas que mais a têm motivado e fascinado. Mas esta vida estimulante e maravilhosa é também parte do mundo em seu conjunto, um mundo em que a fome, o analfabetismo e a doença são a sina diária de grande parte dos seres humanos que ainda existem, assim como causas da morte de muitos que não existem ainda. Uma vida de ociosa e livre expressão é, para a maioria da população mundial, um sonho tão distante que raramente se chega a conceber. O contraste entre essas duas imagens da vida humana conduz a uma pergunta: Que direito tem alguém de viver num mundo feliz, que pode expressar-se livremente, enquanto exista o outro mundo e alguém seja parte dele? (pp. 91-92)

Os debates da filosofia da educação se conjugam com a dimensão evolutiva da espécie humana. Nela se discutem a pluralidade das maneiras humanas de ser em sociedades amplas e complexas, nas quais a diversidade sonha o reconhecimento da diferença. Nessa discussão, Ingold (1995) considera a importância da cultura como "capacidade para gerar a diferença" (p. 8). Trata-se, segundo o autor citado, de um "processo criativo, que se realiza no curso ordinário da vida social, e através dela é que a essência da condição de humanidade se revela como diversidade cultural" (Ingold, 1995, p. 8).

Efetivar a educação inclusiva passa pelo reconhecimento de que "'tornar-se humano' significa tornar-se diferente dos demais seres humanos" 
(Ingold, 1995, p. 8). Porém, e apesar da inédita fase evolutiva em direitos humanos, o aspecto relacional da convivialidade continua frágil no que se refere ao reconhecimento do outro. Um outro diferente, que se manifesta num idioma diferente, possui uma diferente militância político-partidária. Diferente por professar outras crenças, possuir condição econômica diversa, pertencer a uma outra nacionalidade, optar por ser vegetariano ou divergir na cor da pele. Junto às enormes oportunidades de incremento da sociabilidade humana, proporcionada pela tecnociência, surgem também novos riscos de discriminação, de desumanização e de destruição dos nichos vitais e relacionais. Trata-se de uma crise relacional humana com graves riscos para a integridade dos seres humanos, independente de condição social, econômica ou étnica. Concretizar a concepção de pessoa humana, tornar-se alguém e permitir que o outro se torne alguém, e não uma coisa, é ainda uma trama complexa a ser construída.

Ao invés da cultura que gera diferenças, se aposta numa cultura do eu que cultiva o individualismo a ser vivenciado como uma essência natural. É, como expressa Paula Sibilia em $O$ show do eu (2008), um festival de vidas privadas sendo expostas e laureando a "intimidade com espetáculo". A necessidade de exposição pública das intimidades exige, segundo a autora referida, ainda muita reflexão na tentativa de compreender porque as experiências de vida de uma pessoa, mesmo que desconhecida, atrai tanto público nos meios midiáticos. É, como escreve Agamben (2002), uma abstração do outro e sua redução a conceito, um mero dado numérico e estatístico, um ser reduzido a zoé, uma vida nua que perdeu a capacidade de mostrar-se na singularidade do próprio rosto. Diante dessa incapacidade, e uma vez reduzido a conceito, fica fácil intervir sobre ele de forma instrumental e até violenta. É uma espécie de racismo moderno que, segundo Caponi (2004), não está ligado a mentalidades ou ideologias, mas significa vulnerabilidade diante das tecnologias de poder. Ou seja, o Estado funciona, ao utilizar a subdivisão racial da espécie, como possibilidade de eliminação de alguns indivíduos, objetivando a purificação de outros. Esse racismo moderno, que advoga poder, se torna indispensável para tirar a vida de alguém ou reduzir esse alguém a pura zoé - vida nua -, como descrito por Caponi (2004):

Assim que essas populações situadas às margens da sociedade (...) deixam de ser pensadas como sujeitos de direito para passarem a ser pensadas exclusivamente como corpos vivos (...) como pura corporeidade, eles podem 
passar a ocupar esse espaço publicamente perigoso e ambíguo de uma vida nua. (p. 453)

A redução ou condenação de indivíduos à vida nua representa, além de uma atrofia da consciência humana, também um resultado do enfraquecimento da condição de sujeito e da relativização dos valores universais. Por isso mesmo, vivemos em contextos de crise de valores e existencial porque a relativização e o líquido, como se refere Bauman (2001), significam também instabilidade de valores e anúncios da inexistência de portos seguros ou verdades capazes de sustentar rumos definidos. O amanhã/futuro comparece como incerto, porque desejamos o presente e, para tanto, convém negligenciar o passado e o vir-a-ser. $\mathrm{Na}$ condição de presentificados, o que importa é o aqui e agora, vivido como sociedade da rapidez, com suas comidas rápidas, suas exigências fugazes, seus espaços comprimidos pelas velocidades, seus amores rápidos e diversificados, seus resultados e metas sempre em débito.

E é nesse presente múltiplo e complexo, catalisado por conflitos e incertezas, que se realiza a educação escolar, também numa escola da rapidez e dos resultados priorizados. Um contexto com poucas oportunidades para a sensibilidade, poucas oportunidades para perceber as diferenças e a quase inexistente possibilidade para dimensionar a grandeza de cada criança e de cada jovem pela responsabilidade de suas convivências. Esse ambiente escolar encontra-se imerso na mesma crise e perturbações inerentes ao convívio social, produtivo, relacional, político, religioso, entre outros. Se, no além do ambiente escolar, o ser humano vive condições desfavoráveis que Ihe provocam mal-estar psíquico e corporal, a vivência escolar desencadeia similar configuração. A noção de urgência, presente na lógica escolar, juntamente com a insistência conservadora, impedem diferentes e novas experiências, como a experiência do outro. É preciso romper com o tradicional, com a insistência e veneração da cultura da indiferença, da desonestidade e da irresponsabilidade que nos torna cegos à dor e ao sofrimento do outro. Individualismo e solidão são formas de vida e de estar no mundo, silenciado na onipotência do eu. Um eu que pouco se importa com o outro, não admite a legitimidade humana desse outro e é capaz até de descartar os afetos. 
Ainda que fragilizado, é nesse contexto de crise existencial, relacional e ético que a filosofia da educação entende a educação como fenômeno próprio do ser humano. Educar, em seu sentido etimológico, continua sendo um desafio de consolidação de formas de vida contra os poderes (biopoder) que procuram submeter a vida das pessoas, via uso de meios muitas vezes inumanos. A revitalização desse educar requer diferentes subsídios teóricos, dentre os quais destacamos a atitude transdisciplinar.

\section{Atitude transdisciplinar}

Falar em atitude transdisciplinar significa retomar os processos históricos dos modos de vida e dos modos de ser dos seres humanos. Falar de um olhar "trans", transitar, transmigrar, transversal, requer negar a exclusividade dos olhares lineares, objetivos e definidos. É alimentar a expectativa desafiadora de olhar para uma concepção inovadora aliada com a teoria da complexidade. Na concepção da complexidade e transdisciplinar residem concepções de que os conhecimentos são construídos a partir dos referenciais de valorização da diversidade cultural, ou seja, conhecimentos capazes de perceber o mundo em suas múltiplas dimensões e interações desde as épocas mais remotas. A transdisciplinaridade sugere a superação da mentalidade fragmentária, incentivando a visualização das interconexões e a contextualização dos conhecimentos, do ser humano, da vida e do mundo. É uma forma de reivindicar a centralidade da vida e a importância da preservação de sua diversidade, no universo das discussões e das convivências. Entre os ganhos dessa priorização e debates abertos, como cerne da filosofia da educação, está uma possível melhora das condições inclusivas.

Mas é preciso um esforço muito grande para desencadear experiências formativas, como vivências inclusivas, diante da fortaleza reducionista e fragmentária, diante dos normativos e dispositivos de vigilância, controle e punição, tão vivos em nossas mentalidades e ações. Sommerman (2011) salienta que a estrutura ocidental se fez no auge do reducionismo e segundo a lógica aristotélica. Essa lógica demarcava a separação total entre indivíduo observador e objeto e reduzia a possibilidade das vivências para contextos de realidade única e inquestionável. A lógica aristotélica perpassou os séculos, afirmando a necessidade da classificação e condenação de seres 
humanos em seu modo de ser, mesmo que somente o seu fazer tenha sido equivocado diante dos normativos formalmente instituídos.

No contexto da lógica do Terceiro Excluído, o Ocidente enredou-se numa perda desenfreada da globalidade perante um contagioso "empobrecimento da relação dos sujeitos" (Sommermann, 2011, p. 2). A lógica aristotélica do Terceiro Excluído reduz outros níveis de realidades a uma máquina perfeitamente regulada e previsível descartando as possibilidades de existências dinâmicas. Porém, no seio das ciências naturais acenam-se possibilidades de superação do reducionismo, e nesse momento "ocorre algo realmente revolucionário no campo da ordem e da certeza: é o surgimento da desordem e da incerteza" (Morin, 2001, p. 23).

Uma diferente concepção permite reconhecer que nos contextos da desordem se produziu a evolução da condição humana. O modo de ser humano se fez numa aventura cósmica, na qual ordem e desordem eram reconhecidas como complementares e não antagônicas (Morin, 2001). Isso significa um enfraquecimento do paradigma da simplicidade, como acentua Sommerman (2011):

A desordem começou a emergir na ciência quando Boltzman anunciou o segundo princípio da termodinâmica, demonstrando que a entropia tende a crescer no universo. Daí surge a tendência para a degradação, para a desordem nos sistemas... Instaurou-se a presença contínua da ordem e da desordem. Foi um grande golpe no paradigma da simplicidade. (p. 77)

Ainda com dificuldades para reconhecer a complementaridade entre ordem e desordem, como inerente à vida, também negligenciamos as diferenças, o autorrespeito e o respeito aos outros. Muitas escolas, envoltas na cultura do individualismo e da indiferença, reafirmam a massificação e fomentam o universalismo homogêneo negando as individualidades e as experiências de vida, símbolos de desrespeito e indiferença e prenúncios das dificuldades para vivências sociais de acolhida.

Diferentemente, a atitude transdisciplinar, segundo Follmann (2005), "é, sobretudo, uma atitude de humildade, no sentido de estar sempre pronto para acolher a contribuição do outro. Posso dizer que tenho atitude transdisciplinar se minha postura é de reconhecimento do outro" (p. 10). No seio das atitudes de humildade perante o outro e perante os saberes, podemos superar a fragmentação do saber, que "atrofia as possibilidades de 
compreensão e de reflexão" (Morin, 2003, p. 14). Para Morin e Le Moigne (2000), a filosofia é o pensamento capaz de juntar "os conhecimentos, situálos novamente no concreto e na complexidade, e trazer a capacidade de reflexão global de cujas inteligências puramente especializadas são desprovidas" (p. 94). Saberes fragmentados aumentam a incapacidade de articulação de uns com outros, despotencializam o desenvolvimento de uma das qualidades fundamentais da mente humana, que é a aptidão para contextualizar e integrar. E, segundo Morin (2003), o enfraquecimento da visão global implica o enfraquecimento da responsabilidade social e da solidariedade, já que ninguém mais se sente compromissado com o outro.

Para Assmann (2005), a transdisciplinaridade é "o enfoque científico e pedagógico que torna explícito o problema de que um diálogo entre diversas disciplinas e áreas científicas implica necessariamente uma questão epistemológica" (p. 182). Ela transgride as fronteiras epistemológicas e propõe a construção de conhecimentos diferentes transitando "através" das ciências. Na afirmação de D'Ambrosio (1997) ela "repousa sobre uma atitude aberta de respeito mútuo e mesmo de humildade com relação a mitos, religiões e sistemas de explicações e de conhecimentos, rejeitando qualquer tipo de arrogância ou prepotência" (p. 80). Essa abordagem, ao permitir compartilhar com os outros, reconhece a educação inclusiva como imprescindível para também superar o analfabetismo afetivo (Restrepo, 1998). Também Rocha Filho, Souza Basso, e Borges (2007) afirmam que: "É cada vez mais importante assumirmos que dependemos afetivamente uns dos outros (...) o que caracteriza a cognição humana é justamente a afetividade presente nas manifestações de convivência com outras pessoas" (pp. 31-52).

A educação inclusiva, com atitude transdisciplinar, requer o perfil traçado por Severino (2002):

Precisamos de educadores que ensinem o aluno a pensar. Mais do que isto, que despertem o gosto de pensar, que despertem o gosto de aprender e que despertem a experiência insubstituível do diálogo, em que cada um pode se reconhecer como sujeito de ideias, sujeito de palavras, como uma pessoa que tem o que dizer, e que pode dizer, e que será ouvida. (p. 83)

Uma vivência pedagógica, como especificada por Severino, universaliza o direito natural da participação e valorização dos 
conhecimentos, das memórias e histórias individuais e das experiências em vida de cada um dos alunos, sem deixar de considerar suas limitações. Assim, segundo Papst (2005), as "crianças devem ser levadas a sério em vista de suas expressões, esperanças e desejos, introspecções e temores individuais" (p. 16). Trata-se de oportunizar aos alunos a vivência das descobertas e experiências que a relação com o outro proporciona. Papst (2005) sonha com a superação da fria lógica, desvinculada das vivências individuais, para uma relação de respeito e reconhecimento:

O efeito das práticas educativas transdisciplinares poderia servir para que as crianças e os estudantes não sejam paralisados em seu desenvolvimento individual.... A vantagem das práticas educativas transdisciplinares é que as crianças, os estudantes e os seres humanos são levados a sério e tratados respeitosamente. (p. 16)

Assim, a abordagem transdisciplinar pode auxiliar na retomada da interconexão entre as várias áreas do conhecimento, as diversas práticas sociais e o reconhecimento da interdependência entre o "eu" e os outros, possibilitando a eliminação de limites predefinidos.

\section{Processos inclusivos: Uma realidade ainda distante}

É inerente à filosofia da educação participar do debate, ocupando uma posição questionadora e reflexiva sobre o porquê, o como e o para quê os discursos inclusivos ganharem tanto espaço nos debates nas mais diversas organizações humanas. Para a filosofia da educação, a educação inclusiva, ainda que temática atual e recorrente, carece de efetividade nas ações. Nos contextos da atual estrutura organizativa da sociedade, o sonho inclusivo aparece como somente um potencial e não um possível.

Para compreender o porquê de não ser um possível nos apoiamos em Lévy (1997), que afirma que "O possível já está todo constituído, mas permanece no limbo (...) se realizará sem que nada mude em sua determinação nem em sua natureza (...) é exatamente como o real: só lhe falta existência" (pp. 15-16). Isso significa dizer que um possível se torna real sem precisar de criação, ou de produção inovadora, é um completo. Mas a educação inclusiva existe como um potencial; ainda não existe realmente, mas se encontra em realização, ou seja, pode vir a existir ou vir a ser realizada. Ela pode desenvolver-se, aperfeiçoar-se, passar da condição de 
potência ao ato. A passagem da potência ao ato é a atualização e esta "é criação, invenção de uma forma a partir de uma configuração dinâmica de forças e de finalidades (...) uma escolha entre um conjunto (...) uma produção de qualidades novas, uma transformação das ideias, um verdadeiro devir" (Lévy, 1997, pp. 16-17).

Com base em Lévy (1997), a atualização da educação inclusiva e sua passagem a ato não poderão ocorrer de forma intempestiva. Para a filosofia da educação trata-se de um jogo de contradições e ambiguidades que envolve um complexo conjunto de variáveis sociais e culturais que, por sua vez, se retroalimentam de variáveis teóricas, de ideologias e interesses de difícil consenso. A transformação da educação inclusiva em ato é também uma oportunidade para manifestar inconformismo, questionar e problematizar os princípios da existência das variáveis culturais, sociais e pedagógicas.

Transformar a educação inclusiva em ato requer um processo de atualização, ou seja, a tarefa de dar voz e vez ao outro diferente. Um outro diferente com existência própria, mas uma existência constituída em mim e a partir de mim, como destaca Ricoeur (2006): "A alteridade de outrem, como toda outra alteridade, se constitui em (in) mim e a partir (aus) de mim" (p. 169). Esse outro diferente já não pode permanecer como sendo exceção e, como tal, despertar reações de comoção e pena ou então de ojeriza e rejeição.

Refletir sobre a educação inclusiva é permitir-se uma oportunidade para refletir sobre seus propósitos, seus conteúdos, seus suportes humanistas ou salvacionistas e perceber em seu invólucro também a existência de efetivos dispositivos biopolíticos capazes de amplificar serviços de segurança via controle e diminuição do risco social (Veiga-Neto \& Lopes, 2007). O biopoder é considerado uma forma complexa de controle que exclui através de políticas de inclusão. Sobre essa temática, Lopes, Lockmann, e Hattge (2010) concederam entrevista ao Instituto Humanitas Unisinos - IHU, dizendo:

Inclusão, para longe de leituras salvacionistas do termo ou para longe de experiências pontuais, pode ser entendida como uma estratégia biopolítica de gerenciamento do risco social. Ou seja, ao incluir todos os sujeitos, seja na escola, no mercado de trabalho ou no mundo do consumo, está-se, ao mesmo tempo, regulando e controlando suas formas de ser, agir e viver no mundo. (...) a população é constituída como um conjunto que tem suas regularidades, seus riscos próprios, suas ameaças, mas que, estando perto e sendo conhecida, pode ser regulada, controlada e, portanto, governada. 
As autoras evidenciam o significado da expressão 'inclusão', cuja origem etimológica vem do latim clausus. Também claudere, significando algo fechado, confinado. Claustro é o fechamento, o lugar confinado, o recinto e mesmo a prisão. Assim, não necessariamente a inclusão (como in-cludere) significa desejo de ajudar, de aceitar que o outro diferente seja um legítimo outro na convivência. Pode significar não preocupação com o outro, para expressar uma necessidade de regulação e controle de sua forma de ser, agir e viver.

Dessa forma, é pertinente reconhecer que, de maneira geral, a lógica das políticas inclusivas encontra sustento no direito à igualdade; porém, reduzida à garantia de acesso e permanência para todos. Uma vez garantido o acesso, novas formas de exclusão, com base em operações como comparação e classificação, continuam sendo efetivadas e garantem um maior controle e estabilidade social. De maneira geral, as organizações humanas que garantem o acesso e o atendimento a todos tem como princípio a inclusão, mas, ao adotarem mecanismos de comparação e classificação "tornam a diferença mais invisível", gerando novas situações de exclusão, como podemos observar na afirmativa de Stiker (cit. em Plaisance, 2010):

Nas sociedades ocidentais contemporâneas, as formas mais violentas e mais visíveis de eliminação e de exclusão do inválido ou do deficiente não são mais toleradas; porém, formas mais sutis, aparentemente "benévolas", de afastamento operam, por exemplo, em instituições ditas de "acolhimento". A pessoa deficiente não é mais a encarnação do mal, mas continua sendo o mau objeto. A obsessão pela integração testemunha isso. As orientações em favor da integração das pessoas ou, em uma linguagem mais atual, em favor da inclusão, podem ocultar uma vontade "de tornar a diferença invisível socialmente". Pois, se a antiga exclusão acabou, o que se segue é uma integração, uma digestão - e, portanto, uma nova forma de esmagamento. As exclusões que permanecem - numerosas - nada mais são que o reverso dessa tecnologia da absorção. (p. 10)

Diante da ainda distante realização efetiva da educação inclusiva, entendemos que a mesma, como exigente contexto de reconhecimento do diferente, sintoniza com o pensamento complexo. A complexidade, como anteriormente afirmado, implica um processo de conhecimento que envolve relações construídas em coletivos de individualidades, em contextos como se estivessem imbricados formando uma malha, um algo tecido junto. É nessa malha, nesse tecido junto, que cada pessoa, cada manifestação cultural e 
cada conhecimento só faz sentido ou é útil por causa das outras. Bateson (1989), no diálogo com sua filha, escreve: "todo o conhecimento está como se fosse um tricô, ou uma malha, como se fosse um tecido, e que cada peça do conhecimento só faz sentido ou é útil por causa das outras peças" (p. 38). Isso significa admitir que o pensamento complexo é um convite para olhares que desestabilizam, que provocam fissuras, que causam irritação, clamam para o inconformismo, desejam fugir das naturalidades e das acomodações conservadoras. O pensar complexo também convida para perceber a complexidade humana e, para Morin (2003), "O conhecimento da complexidade humana faz parte do conhecimento da condição humana; e esse conhecimento nos inicia a viver, ao mesmo tempo, com seres e situações complexas" (p. 49).

A não compreensão dessa complexidade conserva as desigualdades e confirma nossas representações do real numa lógica que classifica em normais e anormais e a evidente exclusão dos anormais. Fruto de uma representação, segundo Chauvière (2003, cit. em Plaisance, 2010), a

deficiência ocupa um espaço singular onde existem fortes designações e pesadas ignorâncias. Ou a minimizaram para reduzir seu impacto social potencial ou imaginário, ou, ao contrário, a superestimaram para exaltar seu sentido profundo em termos de caridade, de solidariedade ou de cidadania necessária. (p. 11)

Michel Foucault (2010) afirma que a figura do anormal pode ser abordada a partir de três elementos: o monstro humano, o indivíduo a corrigir e o onanista ${ }^{3}$. A condição de anormal é uma forma de representação sociocultural. Ou seja, a caracterização de anormal tem a ver com a estrutura social e cultural tomada como referência. Para Stiker (cit. em Plaisance, 2010), isso "significa dizer que o rótulo e a categorização provêm de estruturações sociais, bem mais que do fato bruto do dano físico ou psíquico.... É a obrigação que tem a sociedade de atribuir o qualificativo de deficiente que cria, socialmente, a deficiência" (p. 11)

Ações inclusivas requerem, além de visões e representações diferentes, a quebra de paradigmas existentes e a superação de preconceitos como "incapazes", "inaptos", "atrasados", todos destoando do padrão aceito. Ela terá melhores chances de efetivação a partir de uma profunda mudança da mentalidade de cada indivíduo e de todos os indivíduos. Na visão de Lima 
(2012), isto supõe uma educação decente, para trabalho decente, não ignorando que o fim último da educação e da aprendizagem é o de permitir que mais seres humanos participem ativamente no processo de construção do mundo social e da sua humanização. Tal prende-se com a criação da sensibilidade de pertença a uma e única espécie: a espécie humana. A sensibilidade de descobrir-se a si como singular e diferente dos demais, mas em condições de conviver com esses demais seres humanos. Uma sensibilidade que quebra o paradigma da existência de um eu independente do outro e abre para a diversidade. Essa quebra, possivelmente, é um alento para firmar o reconhecimento de pertença a uma única espécie, a humana (Morin, 2005).

Mas, vamos, com Agamben (2008), questionar: "Qual é o sentimento último de pertença à espécie humana? E, existe algo que se assemelha a tal sentimento?" (p. 66). Entre os depoimentos trazidos por vítimas do nazismo, Agamben (2008) transcreve:

Os heróis que conhecemos na história e na literatura, quer tenham elevado a voz para falar do amor, da solidão, da angústia do ser e do não-ser, da vingança, quer se tenham erguido contra a injustiça ou a humilhação, não acreditamos que, contudo, tenham sido levados a expressar, como única e extrema reivindicação, o sentimento último de pertença à espécie. Dizer, portanto, que a gente se sentia contestado como homens, como indivíduos da espécie, pode parecer um sentimento retrospectivo, um sentimento de que só depois se teve consciência clara. No entanto, é o sentimento que foi vivido de modo mais imediato e contínuo, e, ademais, era isso, exatamente isso, que os outros queriam. (p. 66)

Ainda, e em outra manifestação, Agamben (2008) transcreve: "A negação da qualidade de homem provoca uma reivindicação quase biológica de pertença à espécie humana" (p. 65). Um sentimento último diante do tudo perdido, a aspiração pela forma biológica do bípede ereto, diante da inexistência da condição de faber, sapiens, demens, ou éthicus. O retorno à animalidade pura, instintiva e de sobrevivência.

Morin (2003) afirma que o reconhecimento da diversidade na unidade permite as relações interpessoais:

Trata-se, ao mesmo tempo, de reconhecer a unidade dentro do diverso, o diverso dentro da unidade; de reconhecer, por exemplo, a unidade humana em meio às diversidades individuais e culturais, as diversidades individuais e culturais em meio à unidade humana. (p. 25) 
A reflexão sobre a diversidade valoriza as individualidades e aumenta a probabilidade da aceitação da legitimidade do outro como diferente, mas igual em espécie. A aceitação das diferenças e do respeito incondicional é um ato de humildade que culmina, normalmente, em atitudes de colaboração. Uma colaboração que se realiza se aceitarmos a interdependência como um emaranhado sistêmico para com os demais seres humanos, o tecido social e o contexto natural. Reforçamos a interdependência com a afirmação de Assmann e Mo Sung (2000):

Quando as pessoas têm uma visão sistêmica da realidade social conseguem perceber que elas são o que são porque fazem parte de um todo social e que elas não existiriam sem a existência de outras pessoas e do sistema social. Elas conseguem perceber que o que afeta uma pessoa ou grupos sociais ou a natureza, que é o meio onde o sistema social reproduz a sua vida, afeta a si próprio e ao seu grupo. Porque nós todos estamos interligados.... É a interdependência como um fato. (p. 81 , grifos nossos)

Como interdependentes não habitamos o mundo na condição de indivíduos, mas convivemos com os demais seres humanos e os contextos sociais construídos pelas diversas identidades conectadas entre si. Um convívio que será tanto mais dinâmico e saudável quanto mais oportunizar o respeito, mesmo àqueles com maiores dificuldades, ou maiores facilidades. Reconhecer as diferenças, acolher um outro, passa pela mudança de mentalidade, a ser iniciada na interioridade de cada ser humano para ser exteriorizada e estendida a todos os humanos.

\section{Conclusão}

Diante da complexidade do cenário educacional e, nele, da educação inclusiva, a filosofia da educação sente-se inspirada a contribuir nos debates. A discussão ultrapassa o simplismo interpretativo para penetrar fundo no debate de concepções fundamentais sobre o sentido da educação inclusiva. Debate que se impõe com renovadas forças para conhecer e aprofundar a temática da inclusão sob a luz da transdisciplinaridade.

Aprender a conviver significa um pilar importante para a perspectiva da educação inclusiva e social e, mais do que isso, significa uma aposta de que a "educação é a possibilidade de constituir um espaço para a diferença, em que possamos enfrentar o outro externo e interno a nós mesmos" (Hermann, 
2010, p. 135). É atribuir credibilidade à educação porque capaz de potencializar a condição de vigilância diante dos abusos e do silenciamento das muitas vozes. Uma educação capaz de alertar para o racionalismo da objetificação que visa a instrumentalização do outro.

Mas essa mudança de mentalidade é complexa, pois simples recomendações teóricas são insuficientes. É preciso resgatar valores esquecidos e não prescrever receitas. Refletir sobre a condição humana, sobre a pertença a uma e única espécie, e valorizar as diversidades para aceitar a diferença como enriquecedora da pluralidade individual e social - 0 que, para Lima (2012,), significa buscar uma educação enquanto direito humano, "que comporte os limites normativos, ético-políticos e morais, que são incompatíveis com fenômenos de amestramento, endoutrinamento ou condicionamento dos seres humanos" (p. 29).

Foi em nome da afirmação do universal que o estranho foi excluído, como foi condenado o diferente e recusado o irracional. Para Hermann (2011), retomar o estranho, o diferente e o considerado irracional requer retomada epistemológica, ética e ontológica, ou seja, tomá-lo "em consideração passou a ser um dos desafios da reflexão filosófica contemporânea, que se vê diante dos limites de seus enfoques epistemológicos, ontológicos e éticos" (p. 6).

Se inclusão significa também fechar e aprisionar (in-claudere), se anormal e deficiente são concepções resultantes de representações sociais, estamos imersos e envoltos em concepções contraditórias. Então, é como universo de concepções contraditórias que os desafios educacionais precisam conhecer e compreender essas diferentes concepções. E é nesse território movediço que a filosofia da educação contribui como esteio reflexivo para ampliar os debates sobre os pressupostos e as implicações da chamada educação inclusiva. Omitir-se e não o fazer, provavelmente, leva a opções simplistas e apressadas, que logo em seguida serão questionadas pela insuficiência e pela fragilidade. De forma séria, profunda e responsável a filosofia da educação pode conduzir as reflexões que precisam reconhecer a complexidade da condição humana para permitir a ampliação da capacidade, primeiramente, de olhar para esse ser humano histórico e desnaturalizado, para depois olhar para o interior de si buscando compreender-se a partir do outro aceito como um igual diferente. Um igual diferente, porque o outro não está somente fora do eu mas também dentro do eu, e é da existência desse 
outro - diferente - que depende o reconhecimento do eu. Compreender-se é compreender o ser humano, é sentir-se sendo um ser humano sensível e singularizado capaz de receber sensivelmente o outro.

\section{Notas}

1 Estudo vinculado ao Projeto 'Observatório da Educação' - Edital: 049/2012: "Estratégias e ações multidisciplinares nas áreas de conhecimentos das Ciências Humanas, Ciências da Natureza e Linguagens, na mesorregião do oeste catarinense: Implicações na qualidade da educação básica" - Capes/ Brasil.

2 Usa-se aqui a expressão 'população' nos termos de Foucault. Para ele, mesmo que cada indivíduo exista em suas particularidades espaciais e temporais, é necessário inserir-se na vida da coletividade = população. Ao designar a população, Foucault também inventou a expressão 'biopoder', como sendo um conjunto de indivíduos, agora pensados na coletividade, formando uma unidade capaz de ser descrita, mensurada, conhecida e, por isso mesmo, governável. Com base no biopoder são "mortos legitimamente aqueles que constituem uma espécie de perigo biológico para os outros. Pode-se dizer que o velho direito de causar a morte ou deixar viver foi substituído por um poder de causar a vida ou devolver à morte" (Foucault, 1999, p. 130).

3 Palavra originária de Onã, que, conforme Gênesis 38, 1-11 relata: Onã, obrigado a casar com a esposa de seu irmão, praticava o coito interrompido, ou seja, os espermatozoides eram ejaculados fora do corpo da mulher, resultando em desperdício. Normalmente é apresentado como sinônimo de masturbação masculina, por esta também implicar em desperdício de espermatozoides.

\section{Referências}

Agamben, G. (2002). Homo sacer: O poder soberano e a vida nua I. Belo Horizonte: UFMG.

Agamben, G. (2008). O que resta de Auschwitz: O arquivo e a testemunha. São Paulo: Boitempo.

Assmann, H. (2005). Reencantar a educação: Rumo à sociedade aprendente. Petrópolis, RJ: Vozes.

Assmann, H., \& Mo Sung, J. (2000). Competência e sensibilidade solidária: Educar para a esperança. Petrópolis, RJ: Vozes.

Bateson, G. (1989). Metadiálogos: Trajectos (2a ed.). Lisboa: Gradiva.

Bauman, Z. (2001). Modernidade líquida. Rio de Janeiro: Jorge Zahar.

Caponi, S. (2004). A biopolítica da população e a experimentação com seres humanos. Ciência \& Saúde Coletiva, 9(2), 445-455. 
D’Ambrosio, U. (1997). Transdisciplinaridade. São Paulo: Palas Athena.

Deleuze, G., \& Guattari, F. (1995). Mil platôs: Capitalismo e esquizofrenia. Rio de Janeiro: Editora 34.

Filho, O. P. (2007). Ação transdisciplinar: É preciso romper o imobilismo, sendo o direito um movimento permanente e evolutivo em busca da justiça. Disponível em http://uj.novaprolink.com.br/doutrina/4300/acao_transdisciplinar_e_preciso _romper_o_imobilismo_ sendo_o_direito_um_movimento_permanente_e_ evolutivo_em_busca_da_justica>

Follmann, J. I. (2005). A universidade exposta à transdisciplinaridade. Revista do Instituto Humanitas Unisinos, 153, 8-12.

Foucault, M. (2010). Os anormais ( $2^{a}$ ed.). São Paulo: Martins Fontes.

Foucault, M. (1999). História da sexualidade: $A$ vontade de saber (13 ${ }^{\mathrm{a}}$ ed.). Rio de Janeiro: Graal.

Hermann, N. (2010). Autocriação e horizonte comum: Ensaios sobre educação éticoestética. ljuí: Editora Unijuí.

Hermann, N. (2011). Breve investigação genealógica sobre o outro. Educação \& Sociedade, 32(114), 137-149.

Ingold, T. (1995). Humanidade e animalidade. Revista Brasileira de Ciências Sociais, 10(28), 39-53.

Lévy, P. (1997). O que é o virtual? (1 ${ }^{\text {a }}$ reimp.). São Paulo: Ed. 34.

Lima, L. (2012). Aprender para ganhar, conhecer para competir: Sobre a subordinação da educação na "sociedade da aprendizagem". São Paulo: Cortez.

Lopes, M. C., Lockmann, K., \& Hattge, M. D. (2010). A articulação entre inclusão e biopolítica. Revista do Instituto Humanitas Unisinos, 334, 20-22.

Marconi, M. A., \& Lakatos E. M. (2008). Metodologia científica. São Paulo: Atlas.

Maturana, H. (2000). Transdisciplinaridade e cognição. In B. Nicolescu (Org.), Educação e transdisciplinaridade (pp. 79-110). Brasília: UNESCO.

Maturana, H., \& Varela, F. (1995). A árvore do conhecimento. Campinas/SP: Psi II.

Maturana, H., \& Yáñez, X. D. (2009). Habitar humano. São Paulo: Palas Athena.

Morin, E. (2001). Por uma reforma do pensamento. In E. P. Nascimento \& A. Veiga-Neto (Orgs.), O pensar complexo: Edgar Morin e a crise da modernidade ( $3^{\mathrm{a}} \mathrm{ed} ., \mathrm{pp}$. 21-34). Rio de Janeiro: Garamond.

Morin, E. (2003). Cabeça bem feita: Repensar a reforma, reformar o pensamento (8 ${ }^{\mathrm{a}}$ ed.). Rio de Janeiro: Bertrand Brasil.

Morin, E. (2005). Os sete saberes necessários à educação do futuro (10 ed.). São Paulo: Cortez; Brasília/DF: UNESCO.

Morin, E., \& Le Moigne, J. L. (2000). A inteligência da complexidade. São Paulo: Editora Fundação Peirópolis.

Nicolescu, B. (1999). O manifesto da transdisciplinaridade. São Paulo: Triom.

Papst, J. (2005). Tornar todos os saberes acessiveis para todos em toda a parte. Revista do Instituto Humanitas Unisinos, 153, 12-14.

Plaisance, E. (2010). Ética e inclusão. Caderno de Pesquisa, 40(139), 13-43. 
Restrepo, L. C. (1998). O direito à ternura. Petrópolis, RJ.: Vozes.

Ricoeur, P. (2006). Percurso do reconhecimento. São Paulo: Loyola.

Rocha Filho, J., Souza Basso, N., \& Borges, R. (2007). Transdisciplinaridade: A natureza íntima da educação científica. Porto Alegre: EDIPUCRS.

Santos, A. (2005). O que é transdisciplinaridade. Rural Semanal, $N^{\circ} 31$ e 32. Disponível em http://www.ufrrj.br/leptrans/arquivos/O_QUE_e_ TRANSDISCIPLINARI DADE.pdf

Severino, A. J. (2002). Educação e transdisciplinaridade. Rio de Janeiro: Lucerna.

Sibilia, P. (2008). O show do eu: A intimidade como espetáculo. Rio de Janeiro: Nova Fronteira.

Sommerman, A. (2011). Complexidade e transdisciplinaridade. Terceiro Incluído Transdisciplinaridade \& Educação Ambiental, 1(1), 77-89.

Veiga-Neto, A., \& Lopes, M. C. (2007). Inclusão e governamentalidade. Educação \& Sociedade, 28(100), 947-963.

Weill, P. (1993). A arte de viver em paz: Por uma nova consciência, por uma nova educação. São Paulo: Gente. 


\title{
THE CONTROVERSIAL INCLUSIVE EDUCATION CHALLENGE: AN INVITATION TO
} THINK THE HUMAN COMPLEXITY

\begin{abstract}
The text recognizes that to make inclusive education requires viewing the human being in a unique way in multidimensional contexts. From this perspective, it calls for the discussion the fragility of the recognition of differences and the importance of the participation of the philosophy of education as a catalyst for discussions on inclusive education. The goal is investigate possible contributions of the philosophy of education as a challenge for a better understanding of how inclusive actions can be potentialized in the universe of complexity and transdisciplinary actions. The text brings theoretical contributions on the transdisciplinary attitude and the possibilities, in the universe of these attitudes, to qualify reflections and inclusive actions. It recognizes that inclusive education exists in potential but it lacks updating. It highlights that transdisciplinarity and philosophy of education can lead the reflections to recognize the complexity of the human condition so that one can look within him/herself seeking a better understanding from the other.
\end{abstract}

Keywords

Inclusive education; Philosophy of education; Transdisciplinarity

EN EL POLÉMICO DESAFíO DE LA EDUCACIÓN INCLUSIVA: UNA INVITACIÓN PARA PENSAR LA COMPLEJIDAD HUMANA

\section{Resumen}

El texto reconoce que la educación inclusiva requiere la visualización de los seres humanos de una manera única en contextos multidimensionales. Desde esta perspectiva, exige la discusión de la fragilidad del reconocimiento de las diferencias y la importancia de la participación de la filosofía de la educación 
como un catalizador para el debate sobre la educación inclusiva. Nuestro objetivo es investigar las posibles contribuciones de la filosofía de la educación como un reto para una mejor comprensión de cómo las acciones inclusivas se pueden aprovechar en el mundo de la complejidad y de las acciones transdisciplinares. El texto trae soporte teórico de la actitud transdisciplinaria y posibilidades, en el universo de estas actitudes, de una contribución para mejorar las reflexiones y acciones inclusivas. Reconoce que la educación inclusiva existe en el potencial y carece de actualización. Destaca que la transdisciplinariedad y la filosofía de la educación pueden conducir las reflexiones para reconocer la complejidad de la condición humana y luego mirar dentro de sí mismo, tratando de comprenderse desde el otro.

Palabras-clave

Educación inclusiva; Filosofía de la educación; Transdisciplinariedad

Recebido em junho/2015

Aceite para publicação em fevereiro/2016

i Programa de Pós-Graduação em Educação, Centro de Ciências Humanas e Sociais, Universidade do Oeste de Santa Catarina, Brasil.

ii Programa de Pós-Graduação em Educação, Centro de Ciências Humanas e Sociais, Universidade Regional Integrada do Alto Uruguai e das Missões, Brasil.

Toda a correspondência relativa a este artigo deve ser enviada para: Roque Strieder, Avenida Cerro Largo 186, Centro, 89898-000, Tunápolis, Santa Catarina, Brasil. E-mail: striederroque@gmail.com 